\title{
Influence of RF power on the proper- ties of sputtered ZnO:Al thin films
}

\section{Aldrin Antony ${ }^{\star}$, Paz Carreras, Thomas Keitzl, Rubén Roldán, Oriol Nos, Paolo Frigeri, José Miguel Asensi and Joan Bertomeu}

\author{
Grup d'Energia Solar, Universitat de Barcelona, Martí i Franquès 1-11, E-08028, Barcelona, Spain
}

Received ZZZ, revised ZZZ, accepted ZZZ

Published online ZZZ (Dates will be provided by the publisher.)

PACS 81.15.cd; 68.55.-a; 73.61.-r; 78.20.-e; 78.66.Li

* Corresponding author: aldrinantony@ub.edu, Phone: +34934039221, Fax: +349340339219

Transparent conducting, aluminium doped zinc oxide thin films ( $\mathrm{ZnO}: \mathrm{Al})$ were deposited by radio frequency (RF) magnetron sputtering. The RF power was varied from 60 to $350 \mathrm{~W}$ whereas the substrate temperature was kept at $160{ }^{\circ} \mathrm{C}$. The structural, electrical and optical properties of the as-deposited films were found to be influenced by the deposition power. The X-ray diffraction analysis showed that all the films have a strong preferred orientation along the [001] direction. The crystallite size was varied from $14 \mathrm{~nm}$ to $36 \mathrm{~nm}$, however no significant change was observed in the case of lattice constant. The optical band gap varied in the range $3.44-3.58 \mathrm{eV}$. The lowest resistivity of $1.2 \times 10^{-3}$ $\Omega \mathrm{cm}$ was shown by the films deposited at $250 \mathrm{~W}$. The mobility of the films was found to increase with the deposition power.

Copyright line will be provided by the publisher

1 Introduction Transparent conducting oxides (TCO) have a wide range of applications due to their high transparency in the visible region and high conductivity. They are widely used in optoelectronics as well as in many fields like architecture, medicine or cosmetics [1-3]. Transparent conducting oxides based on zinc oxide have a wide range of applications due to their non toxicity, bio compatibility, material abundance and low cost. Impurity (B-, Al-, Ga-, In-) doped $\mathrm{ZnO}$ is a n-type degenerate semiconductor with similar electrical and optical properties to ITO [4]. Aluminium doped Zinc Oxide ( $\mathrm{ZnO}: \mathrm{Al}$ ) has become an integral part of the thin film Si solar cells, as the TCO front contact and also as the back reflector component and contributes to the current gain by light scattering improvement [5-8].

$\mathrm{ZnO}$ :Al thin films can be prepared by a variety of techniques, such as low pressure chemical vapour deposition, sol-gel, chemical spray, pulsed laser deposition, DC and RF magnetron sputtering, etc. Among the different techniques RF magnetron sputtering is the widely used one which is quite simple and can be applied on large area. The films deposited by this technique exhibit good adhesion to the substrate and a high packing density [4,7]. In this work $\mathrm{ZnO}$ :Al thin films have been deposited by RF magnetron sputtering. The films were deposited at various powers ranging from $60 \mathrm{~W}$ to $350 \mathrm{~W}$, and the influence of $\mathrm{RF}$ power on the electrical, optical and structural properties of

2 Experimental $\mathrm{ZnO}: \mathrm{Al}$ thin films were deposited onto $10 \times 10 \mathrm{~cm}^{2}$ Corning glass $(1737 \mathrm{~F})$ substrates by radio frequency magnetron sputtering of $\mathrm{ZnO}: \mathrm{Al}$ target (3 inch diameter) containing $98 \mathrm{wt} \% \mathrm{ZnO}$ and $2 \mathrm{wt} \%$ of $\mathrm{Al}_{2} \mathrm{O}_{3}$ of $99.9 \%$ purity. The base pressure in the chamber was always below $2 \times 10^{-6}$ Torr. The sputtering was carried out in argon atmosphere at a pressure of 3 mTorr. The target to substrate distance was fixed at $15 \mathrm{~cm}$ to achieve better homogeneity. The films were deposited at a substrate temperature of $160{ }^{\circ} \mathrm{C}$ and the $\mathrm{RF}$ power was varied in the range 60 to $350 \mathrm{~W}$. All depositions were done for a constant deposition time of $45 \mathrm{~min}$. The deposition rate was found to increase proportional to the power till $250 \mathrm{~W}$ and then reached saturation as shown in Fig. 1. The layers deposited had a good adhesion, physical stability as well as good homogeneity.

The film thickness was measured by using a Dektak 3030 profilometer. The crystallinity of the films was analysed using a powder X-ray diffractometer (PANalytical X'Pert PRO MPD Alpha1 powder system), using copper $K_{\alpha}$ radiation $(\lambda=1.5406 \AA)$ as a source. Transmission and $\mathrm{ZnO}$ :Al thin films was systematically investigated. 
reflection spectra of the samples were recorded by using a UV-vis-NIR spectrophotometer (Perkin Elmer Lambda 19)

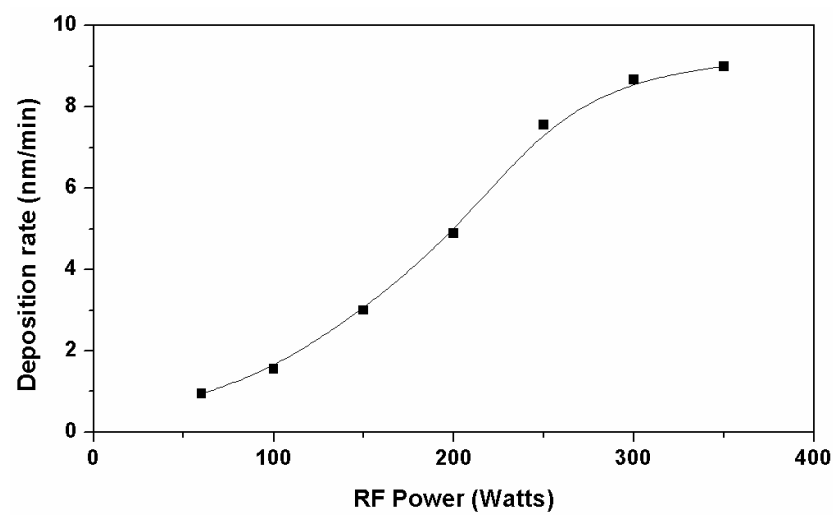

Figure 1 The deposition rate of $\mathrm{ZnO}: \mathrm{Al}$ thin films deposited at different RF powers.

The sheet resistance was measured by using a Jandel RM3 four point probe system. Mobility $(\mu)$ and carrier concentration $(n)$ were determined from the Hall effect measurements by using standard Van der Pauw method in a magnetic field of $0.3 \mathrm{~T}$.

3. Results and discussion The X-ray diffraction (XRD) pattern of the $\mathrm{ZnO}$ : Al films grown by $\mathrm{RF}$ magnetron sputtering at various RF powers is shown in Fig. 2. All the samples showed a diffraction peak at around $2 \theta=34.4^{\circ}$ and an additional second peak of lower intensity at $72.4^{\circ}$.

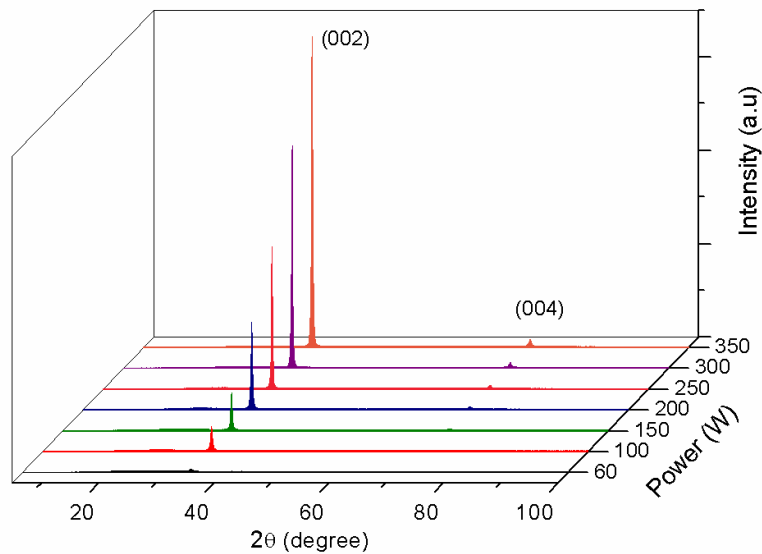

Figure 2 XRD patterns of $\mathrm{ZnO}$ :Al thin films deposited at different RF powers.

The first peak at $34.4^{\circ}$ corresponds to the (002) plane and the second one at $72.4^{\circ}$ to the second diffraction order (004). This implies a hexagonal wurtzite structure having a strong preferred orientation along the [001] direction with the $\mathrm{c}$-axis perpendicular to the substrate surface. $\mathrm{No}^{\mathrm{Al}_{2} \mathrm{O}_{3}}$ related phases could be detected in the XRD patterns. It suggests that aluminium substitutionally replaces zinc in the hexagonal lattice or $\mathrm{Al}$ segregates to the non-crystalline region in grain boundary [10].

The full-width at half maximum (FWHM), the integral breadth $(\beta)$ and the Gaussian and Lorentzian part of the integral breadth $\left(\beta_{G}, \beta_{L}\right)$ were deduced from the pseudoVoigt peak profile fitting of the XRD pattern [11]. The average size of the crystallites $\langle D\rangle$ was calculated by using the integral breadth as shown in Eq. (1).

$$
<D>=\lambda / \beta \operatorname{Cos} \theta
$$

where $\beta$ is the integral breadth, $\lambda$ is the $\mathrm{X}$-ray wavelength, and $\theta$ is the Bragg's angle of diffraction corresponding to the diffraction peak.

The film micro-strain in the diffracting volume $\langle\varepsilon\rangle$ was calculated by using Eq. (2).

$$
<_{\varepsilon}>=\beta_{G} / 4 \tan \theta
$$

where $\beta_{G}$ is the Gaussian part of the integral breadth.

The average crystallite size as a function of the RF power is shown in Fig. 3. The crystallite size increased with power and presented a highest value of $36 \mathrm{~nm}$ at $250 \mathrm{~W}$. However, further increase in RF power resulted in slight decrease of crystallite size. The lowest micro-strain was obtained for the film deposited at $250 \mathrm{~W}$. The lattice parameter value $c$, and the micro-strain of the films are shown in Fig.4. The lattice parameter $c$ was found to be consistent with the standard value $(0.521 \mathrm{~nm})$ and no appreciable change in $c$ value was observed with the further change in RF power.

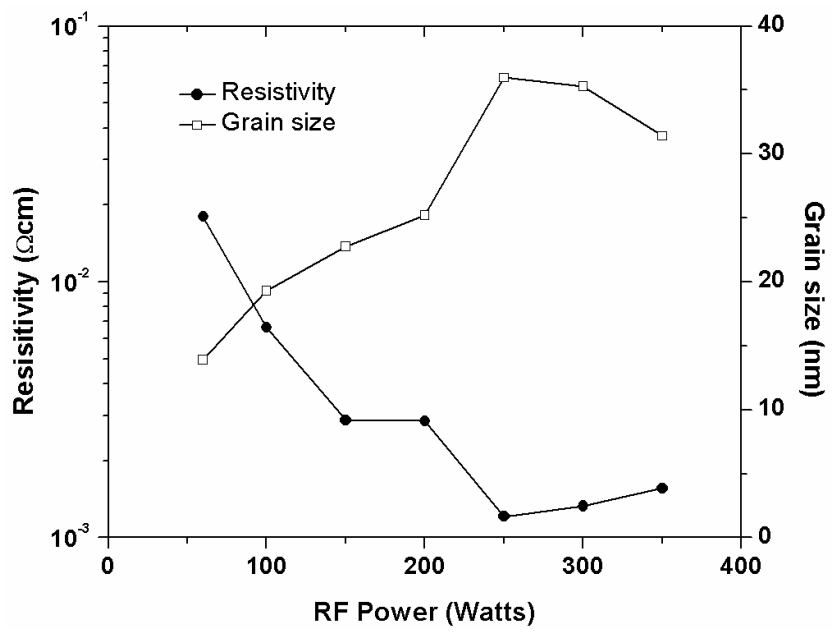

Figure 3 The variation of grain size and electrical resistivity of the $\mathrm{ZnO}$ :Al thin films deposited at different RF powers.

The transmission spectra of the $\mathrm{ZnO}$ : Al films grown at various RF powers are shown in Fig. 5. All the films were highly transparent in the visible region of the electromagnetic spectrum. The average transmission in the visible re- 
gion was more than $80 \%$. At higher wavelengths, the films showed a decrease in transmission with increase in RF power. This is due to the free carrier absorption, which increases with the increase in carrier concentration. The deposition at higher RF powers produces oxygen vacancies in the film resulting in the increase of free carrier absorption [12].

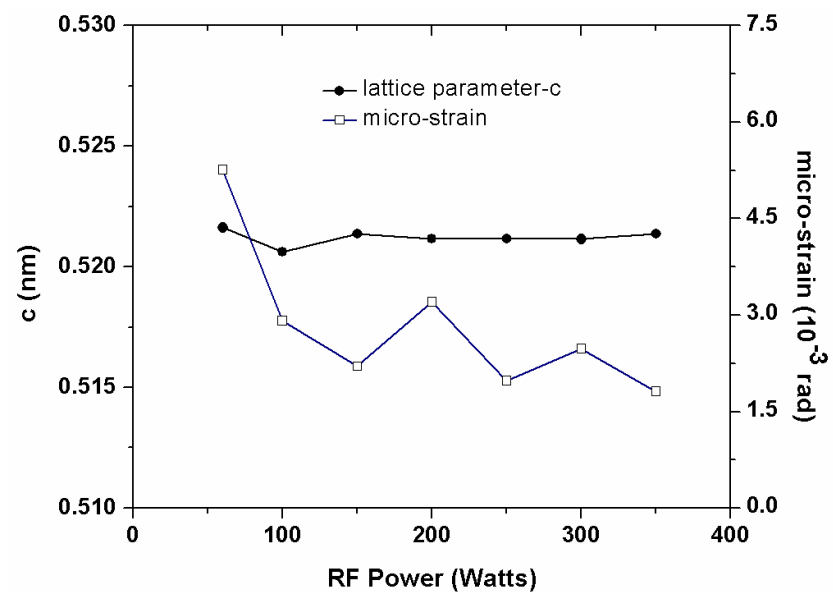

Figure 4 The variation of lattice parameter and micro-strain of the $\mathrm{ZnO}$ :Al thin films deposited at different RF powers.

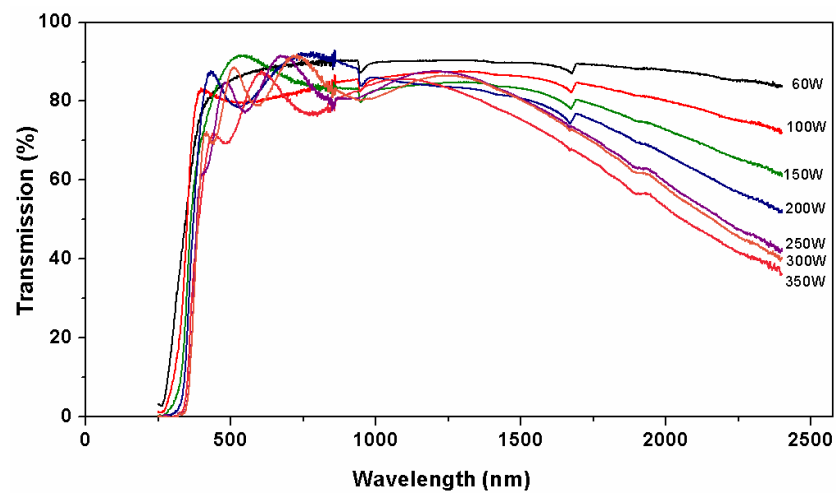

Figure 5 The transmission curves of $\mathrm{ZnO}$ :Al thin films deposited at different RF powers.

The absorption coefficient $(\alpha)$ was determined from the transmittance and reflectance value by means of Eq. (3) [13].

$$
T=(1-R)^{2} e^{-\alpha d}
$$

where $d$ is the layer thickness, $R$ is the reflectance and $T$ is the transmittance.

For direct transitions, as in case of $\mathrm{ZnO}: \mathrm{Al}$ films, the absorption coefficient is given by Eq. 4 [13].

$$
\alpha(h v)=A^{*}\left(h v-E_{g}\right)^{1 / 2}
$$

where $h v$ is the incident photon energy, $E_{g}$ is the bandgap energy and $A^{*}$ is a constant.
The band gap of $\mathrm{ZnO}: \mathrm{Al}$ films was determined from the plot of $(\alpha h v)^{2}$ against $h v$ by extrapolating the linear portion of the curve to $(\alpha h v)^{2}$ equals zero. The calculated values of band gap energies of the $\mathrm{ZnO}$ :Al films deposited at various RF powers are shown in Fig. 6. The inset of Fig. 6 shows a typical $(\alpha h v)^{2}$ against $h v$ plot of $\mathrm{ZnO}$ :Al thin film deposited at $150 \mathrm{~W}$. The band gap values showed an increase with rf power and attained the highest value of 3.58 $\mathrm{eV}$ at $150 \mathrm{~W}$. Beyond $200 \mathrm{~W}$, the band gap value again decreased.

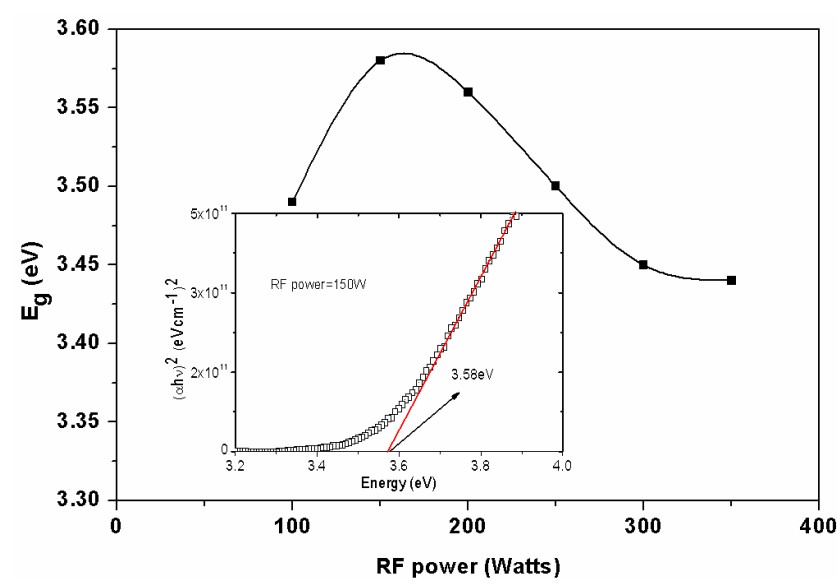

Figure 6 Band gap energies of the $\mathrm{ZnO}$ :Al films deposited at various RF powers. The inset of shows a typical $(\alpha h v)^{2}$ against $h v$ plot of $\mathrm{ZnO}: \mathrm{Al}$ thin film deposited at $150 \mathrm{~W}$.

The resistivity of the as-deposited $\mathrm{ZnO}$ :Al films decreased as power increased till $250 \mathrm{~W}$, where it showed the lowest value $\left(1.2 \times 10^{-3} \Omega \mathrm{cm}\right)$. No significant change in resistivity was observed for higher powers. Fig 3 shows the measured resistivity values of the $\mathrm{ZnO}: \mathrm{Al}$ films deposited at different powers. The conductivity of $\mathrm{ZnO}: \mathrm{Al}$ thin films resulted from the ability of the $\mathrm{ZnO}$ lattice to incorporate substitutional Al atoms without major structural modification as well as from the scattering mechanisms of the free electrons. When $\mathrm{Zn}^{2+}$ is replaced by $\mathrm{Al}^{3+}$, one free electron is created. Doubly charged oxygen vacancy creates two free electrons. The increase in number of free carriers with increase in RF power reduces the resistivity of the films. The increase in mobility and crystallinity of the films are also responsible for the decrease in resistivity with increase in power [14]. The values of carrier concentration and mobility of the films with RF power are shown in Fig. 7. The carrier concentration increased with the sputtering power and reached a maximum value of $1.9 \times 10^{20} \mathrm{~cm}^{-3}$ at $150 \mathrm{~W}$ and then decreased with increase in power. Mobility was low at lower sputtering powers, but showed a rapid increase beyond 200W. A highest mobility of $19 \mathrm{~cm}^{2} \mathrm{~V}^{-1} \mathrm{~s}^{-1}$ was observed for the films deposited at $350 \mathrm{~W}$ power.

In the low power region, the decrease in resistivity can be ascribed to the increase in free carriers created by the substitutional doping. The small crystallite size in this low power region suggests that the low values of mobility 
might be due to the scattering at the grain boundaries. In the higher power region, the XRD analysis showed that the crystallinity improved with RF power, and crystallite size showed a maximum value at $250 \mathrm{~W}$. Bigger crystallites reduced the scattering at the grain boundaries and this in turn gave a higher mobility for the films grown at higher powers. In addition, desorption of oxygen from the film at higher deposition powers may also contribute to this low resistivity.

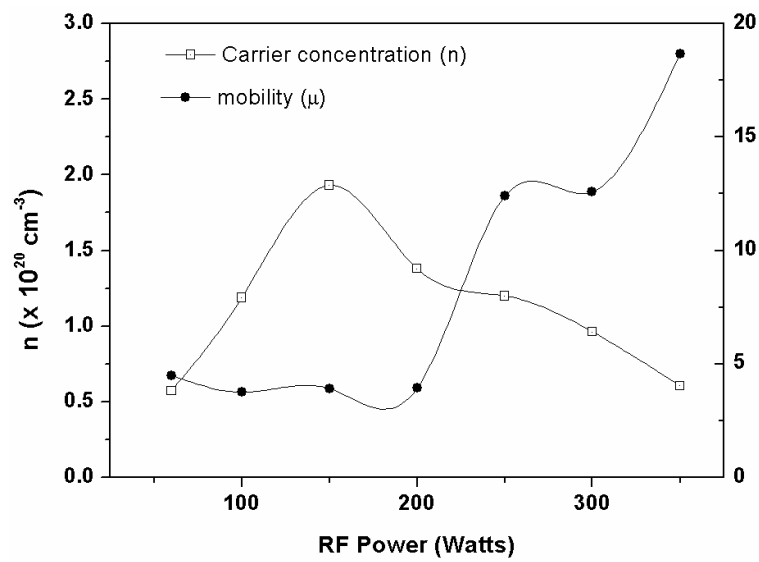

Figure 7 The variation of carrier concentration and mobility of the $\mathrm{ZnO}: \mathrm{Al}$ thin films deposited at different RF powers.

The variation in band gap with RF power can be explained considering the carrier concentration. The band gap increased with the increase in carrier concentration. The highest carrier concentration was measured at the deposition pressure of $150 \mathrm{~W}$, and the energy band gap also showed a maximum value of $3.58 \mathrm{eV}$ at this power. This behaviour of band gap broadening with the increase in carrier concentration is due to Burstein-Moss effect. As the amount of free carriers increases, the Fermi level moves to higher values because the energy required to activate an electron from the valence band to the conduction band is more than the fundamental band gap.

4. Conclusion $\mathrm{ZnO}: \mathrm{Al}$ thin films with high transparency and conductivity were deposited by RF magnetron sputtering at $160^{\circ} \mathrm{C}$. The influence of $\mathrm{RF}$ power on the structural, electrical and optical properties was evaluated. Enhancement of crystallinity with RF power was observed. The film deposited at $150 \mathrm{~W}$ showed the highest carrier concentration $\left(1.2 \times 10^{20} \mathrm{~cm}^{-3}\right)$ and band gap $(3.58 \mathrm{eV})$. The film deposited at $250 \mathrm{~W}$ showed the lowest resistivity of $1.2 \times 10^{-3} \Omega \mathrm{cm}$ and lowest micro-strain. The films deposited at $250 \mathrm{~W}$ and above showed a rapid increase in mobility due to the increase in crystallinity and a highest mobility of $19 \mathrm{~cm}^{2} \mathrm{~V}^{-1} \mathrm{~s}^{-1}$ was obtained for the film deposited at $350 \mathrm{~W}$.

Acknowledgements This work has been supported by the Ministerio de Ciencia e Innovación through the projects CLASICO (ENE2007-67742-C04-03) and MICROSIL08 (PSE120000-2008-1).

\section{References}

[1] C. Klingshirn, Phys. Status Solidi B 224, 3027 (2007).

[2] B.G.Lewis and D.C.Paine, MRS Bulletin 25, 22 (2000).

[3] E. Fortunato, D. Ginley, H. Honoso and D.C. Paine, MRS Bulletin 32, 242 (2007).

[4] W.Yang, Z. Liu, D. Peng, F.Zhang, H. Huang, Y. Xie, Z. Wu, Appl. Surf. Sci. 255, 5669 (2009).

[5] W.Beyer, J.Hupkes and H. Stiebig, Thin Solid Films 516, 147 (2007)

[6] F. Villar, A. Antony, J. Escarré, D. Ibarz, R. Roldán, M. Stella, D. Muñoz, J. M. Asensi, J. Bertomeu, Thin Solid Films 517, 3575 (2009).

[7] A. M.K. Dagamseh, B. Vet, F.D. Tichelaar, P. Sutta and M. Zeman, Thin Solid Flms 516, 7844 (2008).

[8] A. Shah, P.Torres, R. Tscharner, N. Wyrsch, H. Keppner, Science 285, 692 (1999).

[9] S. Fay, L. Feitknecht, R. Schluchter, U. Kroll, E. VallatSauvain and A. Shah, Solar Energy Mater. Solar Cells 90 2960 (2006).

[10] J. Lee, J. Song, Thin Solid Films 516, 1377 (2008).

[11] R. Delhez, T.H. Keijser, E.J. Mittemeijer, Fresenius, J.Anal. Chem. 312, 1 (1982).

[12] M. Nisha and M.K.Jayaraj, Appl. Surf. Sci. 255, 1790 (2008)

[13] J. I. Pankove, Optical Processes in Semiconductors (Dover Publications, New York, 1971), p. 93.

[14] H. Kim, J.S. Horwitz, W.H.Kim, Z.H. Kafafi, D.B. Chisey, J. Appl. Phys. 91, 5371 (2000). 